NASA Technical Memorandum 87242

\title{
A Preliminary Study of Ester Oxidation on an Aluminum Surface Using Chemiluminescence
}

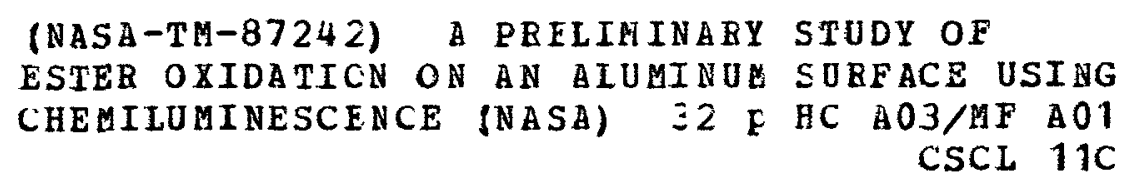

N $86-24835$

Unclas

43032

William R. Jones, Jr., Michael A. Meador, and Wilfredo Morales

Lewis Research Center

Cleveland, Ohio

Prepared for the

1986 Annual Meeting of the American Society of Lubrication Engineers

Toronto, Canada, May 12-15, 1986

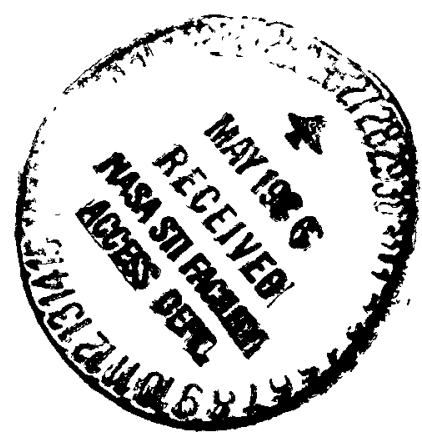




\section{A PRELIMINARY STUDY OF ESTER OXIDATION ON AN \\ ALUMINUM SURFACE USING CHEMILUMINESCENCE \\ William R. Jones, Jr., Michael A. Meador, and Wilfredo Morales National Aeronautics and Space Administration Lewis Research Center Cleveland, Ohio 44135}

\section{Abstract}

The oxidation characteristics of a pure ester (trimethyolpropane triheptanoate) were studied by using a chemiluminescence technique. Tests were run in a thin-film micro-oxidation apparatus with an aluminum alloy catalyst. Conditions included a pure oxygen atmosphere and a temperature range of 176 to $206{ }^{\circ} \mathrm{C}$. Results indicated that oxidation of the ester (containing $10^{-3} \mathrm{M}$ diphenylanthracene as an intensifier) was accompanied by emission of light. The maximum intensity of light emission ( $I_{\max }$ ) was a function of the amount of ester, the concentration of intensifier, and the test temperature. The induction period or the time to reach one-half of maximum intensity $\left(t_{1 / 2}\right)$ was an inverse function of test temperature. Decreases in light emission at the later stages of a test were caused by depletion of the intensifier.

\section{INTRODUCTION}

Advanced aircraft wijl place increased thermal stresses on lubricants and hydraulic fluids. Maximum fluid temperatures in excess of $316{ }^{\circ} \mathrm{C}$ have been forecast for future applications (1) to (3). The primary limitation at these temperatures is normally oxidation. oxidation results in fluid degradation, viscosity increases, and the production of sludge and deposits (4),(5). Over the years many tests have been devised to simulate the oxidizing environment, including the effect of catalytic materials (5). Recently, a sensitive micro-oxidation test has been developed at Pennsylvania State University (6) 
that effectively simulates the conditions (thin lubricant film on a hot metal surface) in a lubricating environment (4), (7).

One phenomenon associated with lubricant oxidation is chemiluminescence. This is the process by which light in the visible range is emitted during the oxidation process (8). Although this 11 ght emission is very weak, modern, highly sensitive detectors, can easily measure this process. Advantages of using emitted light as a means of studying oxidation include the following (9). (10) 1. it is very sensitive, $2 .-1 t^{-}$is noninvasive, 3. the reaction can be followed as a function of time, and 4 . certain kinetic parameters can be extracted from the light emission data. A comprehensive review of the use of chemiluminescence for fuel and lubricant oxidation studies appears in Ref. 11. A brief discussion about oxidation and chemiluminescence appears in the following Background section.

\section{BACKGROUND}

Chemiluminescence (CL) (the light emitted as a result of a chemical reaction) has been recognized since antiquity. It occurs when a product of some chemical reactions is in an excited electronic state. When this molecule relaxes to ground state, a photon is emitted and light is observed in the visible range. Typically, the highly efficient processes occur in biological systems, such as the firefly and marine organisms (12).

Electrochemically generated $C L$, peroxide reactions, and oxidation of hydrocarbons are typically low efficiency processes requiring more sensitive equipment than the human eye for detection and study. This work concerns $\mathrm{CL}$ that results from auto-oxidation (oxidation with molecular oxygen) of organic lubricants. 


\section{REACTION MECHANISM}

\section{Initiation}

Auto-oxidation of an organic compound usualiy proceeds by a free radical chain mechanism. A simplified mechanism is thought to occur as follows (13).

$$
\begin{gathered}
\text { Int }_{2} \stackrel{\text { RI }}{\rightarrow} \text { Int. } \\
\text { Int }+ \text { RH } \rightarrow \text { IntH }+ \text { R. }
\end{gathered}
$$

Here an initiator (Int) produces free radicals (Int•) at reaction rate $\left(R_{f}\right)$. This radical then abstracts a proton from the hydrocarbon $(R H)$ to produce an alkyl radical $(R \cdot)$.

\section{Propagation}

The alkyl radical $(R \cdot)$ reacts with molecular oxygen $\left(0_{2}\right)$ in the propagation step of the chain reaction:

$$
\mathrm{R} \cdot+\mathrm{O}_{2} \rightarrow \mathrm{RO}_{2}
$$

This step produces a peroxy radical $\left(\mathrm{RO}_{2}\right)$ which, in turn, reacts with the parent hydrocarbon (RH) to produce a hydroperoxide $\left(\mathrm{RO}_{2} \mathrm{H}\right)$ :

$$
\mathrm{RO}_{2}+\mathrm{RH} \rightarrow \mathrm{RO}_{2} \mathrm{H}+\mathrm{R} \cdot
$$

This reaction regenerates the original free radical $(R \cdot)$ which propagates the chain.

Termination

The chain reaction can be terminated by radical coupling of two peroxy radicals $\left(\mathrm{RO}_{\dot{2}}\right)$

$$
2 \mathrm{RO}_{2} \rightarrow \mathrm{RO}_{4} \mathrm{R}
$$

or by cross termination of the alkyl radical $\left(R_{\bullet}\right)$ and a peroxy radical $\left(\mathrm{RO}_{2}\right)$

$$
\mathrm{R} \cdot+\mathrm{RO}_{2} \rightarrow \mathrm{RO}_{2} \mathrm{R}
$$

or by reaction of two radicals $(R \cdot)$.

$$
2 R \cdot \rightarrow R R
$$


Normally, when oxygen is present, the concentration of peroxy radicals is much greater than the concentration of alkyl radicals, $\left[R 0_{i}\right]>>\left[R_{\bullet}\right]$ and

reactions (6) and (7) can be neglected. The actual termination reaction is then reaction (5).

\section{CHEMILUAINESCENCE}

\section{Excited States}

In reaction (5), the product $\left(\mathrm{RO}_{4} \mathrm{R}\right)$ is a tetroxide which will further

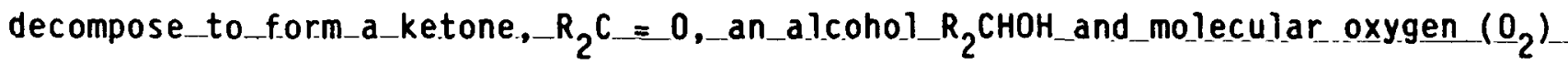

$$
\mathrm{RO}_{4} \mathrm{R} \rightarrow \mathrm{R}_{2} \mathrm{C}=\mathrm{O}+\mathrm{R}_{2} \mathrm{CHOH}+\mathrm{O}_{2} \text { (equation not balanced). }
$$

It is believed that $\mathrm{CL}$ originates from reaction (8) (9). A very small number of the ketone molecules $\left(R_{2} C=0\right)$ produced in this reaction are in an excited singlet or triplet state $\left(R_{2} C=0^{*}\right)$. Perhaps one photon is emitted for every $10^{8}$ to $10^{10}$ terminations.

$$
R_{2} C=0^{*} \rightarrow R_{2} C=0+h v
$$

This inefficiency is, in part, due to quenching of the excited ketone by oxygen or other species (Q):

$$
R_{2} C=0^{*}+Q \rightarrow R_{2} C=0+Q
$$

The intensity of the emitted radiation $(h v)$ is directly proportional to the square of the peroxy radical concentration $\left[\mathrm{RO}_{\xi}\right]^{2}$. This dependence is the basis for determining the concentration of peroxy radicals and thus the kinetics of hydrocarbon oxidation. However, it should be clarified that $\mathrm{CL}$ intensity is not directiy correlatable to overall oxidation rate. The governing rate is that for the excitation process. Essentially, the excited molecules appear in a side reaction. Therefore, it is possible that some species may affect the peroxy radical concentration but not necessarily the oxidation rate. 
Intensifiers :

The intensity of light emission can be greatiy enhanced by the addition of small quantities of chemically inert materials which have high fluorescent efficiencies (10). These "fluors" (F) increase the intensity by energy transfer from the excited ketone to the fluorescent additive:

$$
\begin{gathered}
R_{2} C=0^{*}+F^{*} \rightarrow F^{*}+R_{2} C=0 \\
F^{*} \rightarrow F+h v
\end{gathered}
$$

This may increase the $C L$ sensitivity by several orders of magnitude. Neat DPA alone will chemiluminesce in oxygen at temperatures greater than $180^{\circ} \mathrm{C}$. However, at normal intensifier concentration levels $\left(10^{-3} \mathrm{M}\right)$, its contribution to $\mathrm{CL}$ by its own oxidation is minimal. Emission as a Function of Time

An idealized curve of light emission as a function of time for an oxidation reaction is shown in figure 1. The emission of light gradually increases as oxidation proceeds and the concentration of peroxy radicals increases until steady state is reached. At this point the-iight intensity reaches a maximum ( $I_{\max }$ ). The time to reach this maximum ( $t_{\max }$ ) is a measure of the induction period. More commonly, the time to reach one half of maximum intensity $\left(t_{1 / 2}\right)$ is used.

\section{Dxygen Drop}

If the oxygen flow is shut off while the oxidation reaction is proceeding, there is sometimes an immediate increase in light emission. This occurs because $\mathrm{O}_{2}$ molecules are an effective quenchers for the excited state species (11). The time between oxygen cutoff and the eventual drop in light emission is called the oxygen drop time $\left(t_{F}\right)$.

The oxygen drop time is a direct measure of oxygen consumption. It is therefore a direct measure of the reaction rate. The oxygen concentration in 
the 011 film at the oxygen cut off point must be known in order to calculate oxygen consumption.

\section{APPARATUS}

\section{Micro-oxidation Apparatus}

Figure 2 illustrates the micro-oxidation apparatus used in this study. This is a modification of the oxidation apparatus developed at Pennsylvania State University (6),(7). It consists of two heat resistant glass sections. The outer (or lower) section accepts the catalyst specimen. The material to be oxidized is placed on the catalyst surface. The catalyst specimen is held in place by an annular glass ring on the base of the outer, or lower, section.

The inner (or upper) section contains the holder for the fiber-optic probe to sense the light emission from the catalyst surface. This assembly consists of two vertical, concentric tubes forming an annular space for reduction of heat transfer to the probe which contains a heat-sensitive epoxy. The bottom of each of these tubes is sealed with a quartz window. Quartz was used to prevent absorption of the emitted light before it can be detected. The upper section also contains a gas inlet tube for oxygen or argon flow. Both sections are connected by a ground glass, joint. The distance from the end of the fiber optic probe to the top of the ester film is approximately $1.5 \mathrm{~cm}$.

\section{Chemiluminescence Apparatus}

A schematic diagram of the chemiluminescence apparatus is shown in Fig. 3. The system consists of the fiber-optic probe, a photomultiplier tube (PMT) and housing, an amplifier-discriminator, a high voltage power supply, a rate meter, and a recorder.

The fiber-optic probe is a bundle of quartz fibers $(50 \mathrm{~cm}$ long) and covered with a flexible stainless steel sheath $(\sim \mathrm{mm} 0 . \mathrm{d}$.$) . One end of the$ probe is inserted into the micro-oxidation apparatus. The other end is 
attached to a flange on the PMT housing, containing a manually operated shutter. The photomultiplier tube has a dark current of 4 nA and a spectral response range of 160 to $850 \mathrm{~nm}$. The housing also contains a thermoelectric refrigerated chamber in order to cool the photomultiplier-tube cathode to approximately $40^{\circ} \mathrm{C}$ below ambient.

The input pulse from the PMT is fed into amplifier-discriminator mounted inside the PMT housing. The output from the amplifier-discriminator is connected to a ratemeter which measures the rate of input pulses. A $30 \mathrm{sec}$ time constant was used in these studies. The count rate is displayed on a panel meter. There is also an analog voltage output to drive a strip chart recorder.

\section{Bath and Light-Tight Enclosure}

A high temperature $\left(250^{\circ} \mathrm{C}\right)$ constant temperature bath was used in these studies. A high viscosity silicone fluid served as the heat transfer medium. Bath specifications indicated temperature control to $\pm 0.1{ }^{\circ} \mathrm{C}$. However, due to the high silicone viscosity, temperature variations of $\pm 1{ }^{\circ} \mathrm{C}$ were common.

A cylindrical aluminum sleeve is mounted in the bath opening $(10 \mathrm{~cm}$ long, $5 \mathrm{~cm} \mathrm{1.d.} \mathrm{and} 6.5 \mathrm{~cm} 0 . \mathrm{d}$.$) . About 7 \mathrm{~cm}$ of this sleeve was submerged in the bath fluid. A platinum resistance thermocouple is mounted vertically in the side of the sleeve to a depth of $9 \mathrm{~cm}$. This couple is connected to a digital readout accurate to $\pm 0.1{ }^{\circ} \mathrm{C}$. The readout also has a minimum/maximum recall mode to determine the temperature range during an experiment.

The bath and PMT housing are located inside a light-tight metal box located in the corner of a fume hood. A handle on the top of the box is used to operate the PMT shutter remotely. 


\section{PROCEDURE}

At least $2 \mathrm{hr}$ before a test, the PMT system was turned on and allowed to stabilize. The thermoelectric cooling system was maintained continuously. The supply voltage to the PMT was kept constant at a setting of $1000 \mathrm{~V}$.

The micro-oxidation apparatus was thoroughly cleaned with trichlorotrifluoroethane and allowed to air dry. The catalyst was cleaned with trichlorotrifluoroethane and then scrubbed with a paste of submicron alumina. The catalyst was rinsed with tap water and then distilled water and allowed to air dry. The catalyst was weighed and then placed with forceps in the bottom of the lower section of the micro-oxidation apparatus. The catalyst and lower section of apparatus were weighed together. Then six drops of ester were placed on the catalyst surface by pipette. The section was reweighed to determine exact amount of added ester.

The upper apparatus section was inserted into the lower section and the device was purged with argon for $5 \mathrm{~min}$ at room temperature (flow rate $>75 \mathrm{ml} / \mathrm{m}(\mathrm{n})$. Next the assembled apparatus was placed in a steel holder on a hot plate previously heated to $130^{\circ} \mathrm{C}$. The apparatus was purged with argon at this temperature for 20 to $25 \mathrm{~min}$ to remove dissolved oxygen and water from the ester film.

At this point the apparatus was placed in the aluminum block in the bath which had previously been heated to test temperature. The fiber-optic probe was inserted in the upper section of the apparatus. A high flow rate of air is directed into the annular region around the fiber-optic probe for cooling. The top of the apparatus was covered with aluminum foll to block any stray light, and the front cover of the enclosure was put in place.

While the apparatus was being initially purged, a baseline count rate with the PMT shutter closed was determined. After the lighttight box was closed, the PMT shutter was opened and a new baseline was measured during 
temperature equilibration. After 20 to $30 \mathrm{~min}$, the argon flow was turned off and simultaneousiy the oxygen flow was begun. The intensity of emitted light was recorded continuousiy on a strip chart recorder. After the light intensity reaches a maximum, the test was continued for another 5 to 15 min and then the oxygen and argon flows were exchanged.

The box was opened and the apparatus was removed and allowed to c001, still under an argon purge. The two sections were separated and the lower part was weighed to determine the ester weight loss. Then $4 \mathrm{ml}$ of chloroform was added to the lower section to dissolve the remaining ester. This sample was retained for high-pressure liquid chromatographic analysis (HPLC). The catalyst was thoroughly rinsed with trichlorotrifluoroethane, allowed to air dry and weighed, to determine whether deposits remained on the catalyst.

\section{MATERIALS}

Lubricant

An ester (trimethyolpropane triheptanoate) TMPTH was used in these studies. Its structure is shown in Fig. $4(a)$ and some chemical and physical properties are given in Table $I$.

\section{Intensifier}

9,10-Diphenylanthracene (DPA) was used as an intensifier to increase the efficiency of light emission. Its purity was 99 percent and was used as received. Its structure is shown in $\mathrm{Fig} .4(\mathrm{~b})$.

\section{Catalyst}

The catalyst material used was aluminum alloy 2024 which has the following nominal composition: Copper 3.8 to 4.9 percent, manganese 0.3 to 0.9 percent, magnesium 1.2 to 1.8 percent, BALANCE-aluminum. The dimensions of the catalyst are illuṣtrated in Fig. 5. This alloy was chosen because it is the aluminum alloy used in the standard oxidation-corrosion test developed by the Air Force (14). 


\section{RESULTS}

I max as a Function of Time

Light emission data as a function of time are shown in Fig. 6 for various temperatures. Maximum light emission increases with increasing temperature. The general form of the emission curve, was a bulldup to $I_{\max }$ and then a gradual dropoff. The higher the temperature, the more rapid the dropoff of light emission. The maximum light emission ( $I_{\max }$ ) and the time for the emission to reach one-half of $I_{\max }$ are determined from these curves. These data are sumarized in table II:

$I_{\text {max }}$ as a Function of Sample size

A few tests were run at nearly constant temperature $\left(178.3\right.$ to $\left.179.5{ }^{\circ} \mathrm{C}\right)$ with different sample sizes. I $I_{\max }$ as a function of sample size appears in Fig. 7. An essentially linear relationship between $I_{\max }$ and sample size was observed. It became apparent that in order to correlate the $I_{\max }$ data some form of normalization was necessary. Even using the same number of drops of lubricant yielded slightly different weights. Therefore, a normalized maximum emission ( $I_{\max }^{\star}$ ) was calculated dividing the observed $I_{\max }$ by a normalized weight. This weight was calculated by dividing the lubricant sample size from each test by 0.0512 , which was the minimum sample size in this test serles (from test $B-36$ ). These normalized weights and the calculated $I_{\max }^{*}$ are also summarized in Table II.

$I_{\max }^{*}$ Versus Temperature

Normalized maximum light emission $\left(I_{\max }^{\star}\right.$ ) as a function of temperature appears in Fig. 8 . The data is fitted with a geometric least squares equation.

Log $I_{\max }^{*}$ as a Function of $1 / T$

The data from figure 8 are replotted in Arrhenius fashion in Fig. 9. Here the log of the normalized maximum light emission is plotted as a function 
of the reciprocal of the absolute temperature by using a linear least square fit. A correlation coefficient of 0.951 was obtained.

${\underline{\log }\left(t_{1 / 2}\right)^{-1} \text { as a Function of. } 1 / T}$

Another Arrhenius plot appears in Fig. 10. Here the $\log$ of the

reciprocal of the time to reach one-half maximum light emission $\left(t_{1 / 2}\right)^{-1}$ is plotted as a function of the reciprocal of absolute temperature. A correlation coefficient of 0.962 was determined.

\section{DISCUSSION}

\section{Chemiluminescence as Function of Time}

As expected, very low background levels of light emission (50 to 100 counts per second) were obtained while the apparatus was being purged with argon. After the oxygen flow was initiated, there was no change in light intenstty for approximately $45 \mathrm{sec}$. Then light emission increased for approximately $30 \mathrm{sec}$. The rate of increase decreased at this point but still continued to build up to a maximum.

The initial delay is most likely due to the time required for the argon to be swept out of the chamber by the oxygen and for the subsequent oiffusion of oxygen into the lubricant film.

The initial increase in light emission which produces a small shoulder on the emission curve may be due to the presence of adventitious peroxides or other: species which may cause enhanced chemiluminescence. Similar behavior has been reported in oxyluminescence studies of polymers (15).

One would now expect a bufldup to steady state and a maximum level of light emission, as indicated in the idealized curve of Fig. 1. However, the maximum emission is sustained only for a short time. There is a dropoff in intensity which is more pronounced as test temperature increases. This could be caused by one of several factors: 
(1) The oxidation rate is decreasing because of high conversion of the starting material (ester).

(2) The oxidation rate decreased because of the formation of natural inhibitors.

(3) The oxidation rate was constant but the quantum efficiency of the light emission reaction decreased because of increased quenching of the excited state by some product formed during the oxidation process.

(-4)-The-oxidation-rate-was-constant-but-the-intens-ifier-(DPA)-was-being. depleted.

One drawback of the micro-oxidation apparatus is that at high temperatures much of the material is degraded (sometimes more than 50 percent) (5). However, because of the sensitivity of the CL method, tests can be run at much lower temperatures (generally less than $200^{\circ} \mathrm{C}$ ) where conversion may be only a few percent.

HPLC analysis of the oxidized lubricant as a function of test time indicated that the oxidation rate was not decreasing and that much starting material remained. Therefore possibilities (1) and (2) can be excluded.

There is no easy way to determine whether possibility (3) occurred. However, HPLC analysis of the oxidized lubricant indicated a continual decrease in DPA concentration as a function of test time (Fig. 11). Size exclusion chromatography showed almost a complete loss of DPA after $30 \mathrm{~min}$ at 190 to $193{ }^{\circ} \mathrm{C}$. The same analys is showed a continued increase in high-molecular weight products of the oxidized ester.

Several tests were then performed by using different molar concentrations of DPA $\left(0.5 \times 10^{-3}, 2 \times 10^{-3}\right.$ and the standard $\left.1 \times 10^{-3}\right)$ at 191 to $192{ }^{\circ} \mathrm{C}$. $I_{\max }$ (not normalized) is plotted as a function of molar concentration of DPA in Fig. 12. The amount of test lubricant was nearly constant for each test. 
It is apparent that a linear relationship exists between $I_{\text {max }}$ and the amount of DPA.

\section{INSENSIFIER DEPLETION}

The CL literature does not address the problem of intensifier depletion. All reported work has been done on bulk solutions for which intensifier depletion is apparentiy not significant. In addition, most tests were performed at relatively low temperatures. Lundeen and Livingston do report a linear dependence of intensity on intensiffer concentration (16). From their tests they also reported that $C L$ intensity rose to a maximum and then slowly decreased. However, they gave no reason for this phenomenon.

Depletion of additives from thin films was reported by Sniegoski (17). He showed that two commonly used antioxidants were rapidly depleted from thin oil films placed on bearing steels and exposed to air at room temperature. Therefore, it may not be surprising that DPA was depleted at elevated temperatures. However, the loss of DPA was not solely due to evaporation. A test run in argon (B-47) at $194^{\circ} \mathrm{C}$ showed little depletion of DPA. Therefore, depletion is definitely related to the oxidation process.

The exact fate of the DPA is not known. It is either oxidized to a more volatile component or it adsorbed on the catalyst specimen. At any rate, for future work, a different intensiffer will be tried, such as 9,10 dibromoanthracene or a heavier molecule, for example rubrere.

It is possible to run tests without added intensiffer. However, when that was tried (test B-37) light emission was very low (approximately an order of magnitude less than tests with $10^{-3} \mathrm{M}$ DPA) at a test temperature of $179{ }^{\circ} \mathrm{C}$. However, other tests (not reported here) do show increased $\mathrm{CL}$ wh increasing amounts of neat ester.

It should be noted that an intensifier has a function other than just increasing the efficiency of the emission process. When hydrocarbons oxidize, 
they often form fluorescent products which can then affect the light emission in an unpredictable manner. The addition of an intensifier effectively masks this problem.

Since there is a linear dependence of light emission on intensifier concentration, CL emission curves can be corrected if the actual intensifier concentration is known. For example, taking data from the size-exclusion curves of Fig. 11, one can construct a curve for DPA concentration as a function time in the temperature range of 190 to $193{ }^{\circ} \mathrm{C}$. These data appear in Fig. 13 and are represented with an exponential least-squares-fit.

The actual light emission as a function of time for test B-53 (temperature, $191.9^{\circ} \mathrm{C}$ ) appears in figure 14 . When the data from $\mathrm{Fig} .13$ are used, and a linear dependence of emission on DPA concentration is assumed, an adjusted emission curve is obtained. This curve represents the actual light emission as a function of time without regard to intensifier depletion. The adjusted curve corrected for DPA depletion shows a plateau which is the expected feature at steady state.

There are two other important points to be drawn from this corrected curve. First, the maximum light emission ( $I_{\max }$ ) is much greater than the experimentally obtained data. Obviously, this difference depends on temperature, and it is more pronounced at higher temperatures. In addition, the time to reach the plateau on the corrected curve and $I_{\max }$ for the actual emission curve are different. Therefore, $t_{1 / 2}$ is different. These factors must be considered in the following discussion on activation energy.

\section{Activation Energy}

Some kinetic parameters, such as activation energies can be determined from $C L$ data. It has long been recognized that kinetic data over a wide temperature range can be represented by an empirical equation proposed by Arrhentus (18): 


$$
k=s e^{-E} a^{/ R T}
$$

where $k$ is the rate constant, $s$, is the pre-exponential factor, $E_{a}$, the activation energy, $R$, the gas constant, and $T$, the absolute temperature. In logarithmic form

$$
\log k=\frac{-E_{a}}{2.303 R T}+\log s
$$

Therefore, a straight line should be obtained when $\log k$ is plotted as a function of the reciprocal of the absolute temperature.

It has been shown that $k$ is proportional to $I_{\max },\left(t_{1 / 2}\right)^{-1}$, and $\left(t_{F}\right)^{-1}$ (10). The activation energy calculated from the slope of $\log I_{\max }$ as a function of $(T)^{-1}$ is usually related to the propagation reaction (Eq. (4)). When oxygen diffusion into the $011 \mathrm{f} 1 \mathrm{~lm}$ is rate limiting, $E_{I_{\max }}=2 E_{\text {PROPAGATION }}$ (9). $E_{I_{\max }}$ was found to be $22 \mathrm{kcal} / \mathrm{mole}$ (from fig. 9). Therefore, EPROPAGATION is approximately $11 \mathrm{kcal} / \mathrm{mole}$. The same treatment of $\left(\mathrm{t}_{1 / 2}\right)^{-1}$ (Fig. 10) yielded an $E_{A}$ of $25 \mathrm{kcal} / \mathrm{mole}$. This is related to the initiation reaction. For auto-oxidation reactions, in the absence of added initiators, the major source of free radicals is probably thermal decomposition of hydroperoxide (13).

$$
\mathrm{ROOH} \rightarrow \mathrm{RO} \cdot+\cdot \mathrm{OH}
$$

This treatment of $I_{\max }$ and $t_{1 / 2}$ data yielded reasonable values for activation energies. However, in light of the discussion involving intensifier depletion, it is obvious that both values would be changed considerably if intensifier concentration were constant.

\section{Oxygen Drop Experiments}

As discussed earlier, $t_{F}$ or the time for intensity to drop off after the oxygen flow is cut off, can be related to the oxidation rate itself. However, a rise in light intensity after oxygen cutoff was not observed in 
these studies. Since very little oxygen is contained in the thin film, it may be depleted before any decrease in quenching can be detected. It has also been reported that when an intensifier is used, the lifetime of the emitting species is sometimes shortened to such an extent that oxygen drop is not observed (19). The long time constant (30 sec) used in gathering these data also reduces the probability of detection.

\section{INITIATOR}

A1- tes-t--except-B-38 were run without-added initiators. . In-B-38, $10^{-2} M$ azoisobutyronitrile (AIBN) was added. An induction period of 10.8 min was obtained for this test compared with $15.0 \mathrm{~min}$ for test B-35 run at a comparable temperature without an. initiator. Although this variation is not much greater than test to test reproducibility, future work should employ an initiator to improve induction period reproducibility.

It can be concluded that chemiluminescence is a viable technique for. studying oxidation phenomena in thin films. However, problems of intensifier depletion and poor temperature control must be addressed.

\section{SUMMARY OF RESULTS}

A chemiluminescence technique was used to study the oxidation characteristics of a pure ester (trimethyolpropane triheptanoate). Tests were conducted in a thin film micro-oxidation apparatus. with an oxygen atmosphere over a temperature range of 176 to $206{ }^{\circ} \mathrm{C}$. The following results were obtained:

(1) The oxidation of the ester was accompanied by emission of light in the wavelength range of 160 to $850 \mathrm{~nm}$.

(2) Maximum light emission was a function of the amount of ester, concentration of intensifier, and temperature.

(3) Log of the induction period (the time to reach one-half of maximum intensity) was inversely proportional to temperature. 
(4) Decreases in light emission at the later stages of a test were caused by depletion of intensifier.

\section{REFERENCES}

(1) Zaretsky, E.V., and Ludwig, L.P.; "Advancements in Bearings, Seals, and Lubricants," Aircraft Propulsion, NASA SP-259 pp. 421-463 (1971).

(2) Sliney, H.E., "Bearings, Lubricants, and Seals for the Space Shuttle. Space Transportation System Technology Symposium, Vol. III - Structures and Materials," NASA TM X-52876 pp. 289-296 (1970).

(3) Loomis, W.R., "Overview of Liquid Lubricants for Advanced Aircraft," NASA TH-83529 (1982).

(4) Jones, W.R., Jr., and Morales, W., "Thermal and Oxidative Degradation Studies of Formulated C-Ethers by Gel Permeation Chromatography, "NASA TP-1994 (1982).

(5) Jones, W.R., Jr., "A Review of Liquid Lubricant Thermal/0xidative Degradation," NASA TM-83465 (1983).

(6) Critkovic, E., Klaus, E.E., and Lockwood, F., "A Thin-Film Test for Measurement of the 0xidation and Evaporation of Ester-Type Lubricants," ASLE Trans., 22, pp. 395-401 (1979).

(7) Lockwood, F., "Ester Oxidation Under Simulated Boundary Lubrication Conditions," Pho Thesis, Pennsylvania State University (1978).

(8) Vasil'ev, R.F., "Chemiluminescence in Solutions," Sov. Phys. Usp. (Engl. Trans 1.) 9, pp. 504-524 (1967).

(9) Mendenha11, G.D., "Analytical Applications of Chemiluminescence, Angew. Chem. Int. Ed. Engl., 16, 1977, pp. 225-232 (1977).

(10) Nathan, R.A., "Chemiluminescence for the Determination of the Kinetics and Mechanism of Jet Fuel Oxidative Degradation," Battelle Columbus Laboratories (AD-779335) (1974). 
(11) Clark, D.B., Weeks, S.J., and Hsu, S.M., "An Introduction to Chemiluminescence Methods for Lubricant Oxidation Studies." National Bureau of Standards, NBSIR-82-2490 (1982).

(12) McCapra, F., "Chemiluminescence of Organic Compounds," Progress in Organic Chemistry, Vol. 8, W. Carruthers and J.K. Sutherland, eds., John Wiley and Sons, New York, pp. 231-277 (1973).

(13) Sheldon, R.A.; and Kochi, J.K., Metal-Catalyzed Oxidations of Organic Compounds-,-Academic-Pres.- (1.981)-.-

(14) Harsacky, F.J. and Dolle, R.E., "A Chronological History of the Development of High Temperature Oxidation-Corrosion Evaluation Methods Including an Improved Micro Oxidation-Corrosion Evaluation Methods Including an Improved Micro Oxidation-Corrosion Procedure for the Investigation of Advanced Gas Turbine Engine Lubricants," AFML-TDR-64-291 (AD-464417), Air Force Matertals Lab. (1965).

(15) George, G.A., "An Oxyluminescence Investigation of the Auto-0xidation of Nylon 66," Polymer Degradation and Stabflity. Applied Science Publishers Ltd., England pp. 217-236 (1979).

(16) Lundeen, G. and Livingston, R., "Chemiluminescence of Hydrocarbon Oxidation," Photochem. Photobiol., 4, pp. 1085-1096 (1965).

(17) Sniegoski, P.J., "Antioxidant Depletion from Lubricant Thin Layers," Lubr. Eng., 37, pp. 286-290 (1981).

(18) Hammes, G.G. and Andur, I., Principles of Chemical Kinetics, Academic Press, (1978).

(19) Vassil 'EV, R.F., "Chemiluminescence in Liquid-Phase Reactions," Progress in Reaction Kinetics, Vol. 4, G. Porter, ed., Pergamon Press, pp. 305-52 (1967). 
TABLE I. - PHYSICAL AND CHEMICAL PROPERTIES OF

TR IMETHYOLPROPANE TRIHEPTANOATE

$$
\begin{aligned}
& \text { Viscosity, } \mathrm{CS} \\
& \text { at } 99^{\circ} \mathrm{C} \\
& \text { at } 38{ }^{\circ} \mathrm{C} \\
& \text { at }-18{ }^{\circ} \mathrm{C} \\
& \text { at }-40{ }^{\circ} \mathrm{C} \\
& \text { Pour point, }{ }^{\circ} \mathrm{C}
\end{aligned}
$$

Specific gravity, $25^{\circ} \mathrm{C}$

Color, ASTM

Flash point, ${ }^{\circ} \mathrm{C}, \mathrm{COC}$

Fire point, ${ }^{\circ} \mathrm{C}, \mathrm{COC}$

Auto ignition temperature, ${ }^{\circ} \mathrm{C}$, ASTM 02155

Morsture content, percent

Foaming tendency, ASTM D892

Sequence I

Sequence II

Sequence III

Evaporation, wt \%

, After $6.5 \mathrm{hr}, 204{ }^{\circ} \mathrm{C}$

After $22 \mathrm{hr}, 149^{\circ} \mathrm{C}$

Shell 4-ball wear test

Scar diameter, mm (54 $\left.{ }^{\circ} \mathrm{C}, 600 \mathrm{rpm}, 1 \mathrm{hr}\right)$

$1 \mathrm{~kg}$ load

$10 \mathrm{~kg} \mathrm{load}$

$40 \mathrm{~kg}$ load

3.5

15.2

287

2400

$-68$

0.963

1.0

238

216

463

0.02

N11

N1 1

NiT

6.0

0.38

0.21

0.43

0.57 
TABLE II. - SUMMARY OF TEST DATA - LUBRICANT: TRIMETHYOLPROPANE TRIHEPTANOATE; CATALYST: ALUMINUM ALLOY 2024; ATMOSPHERE: OXYGEN; INTENSIFIER: 9.10 OIPHENYLANTHRACENE $\left(10^{-3} \mathrm{M}\right)$

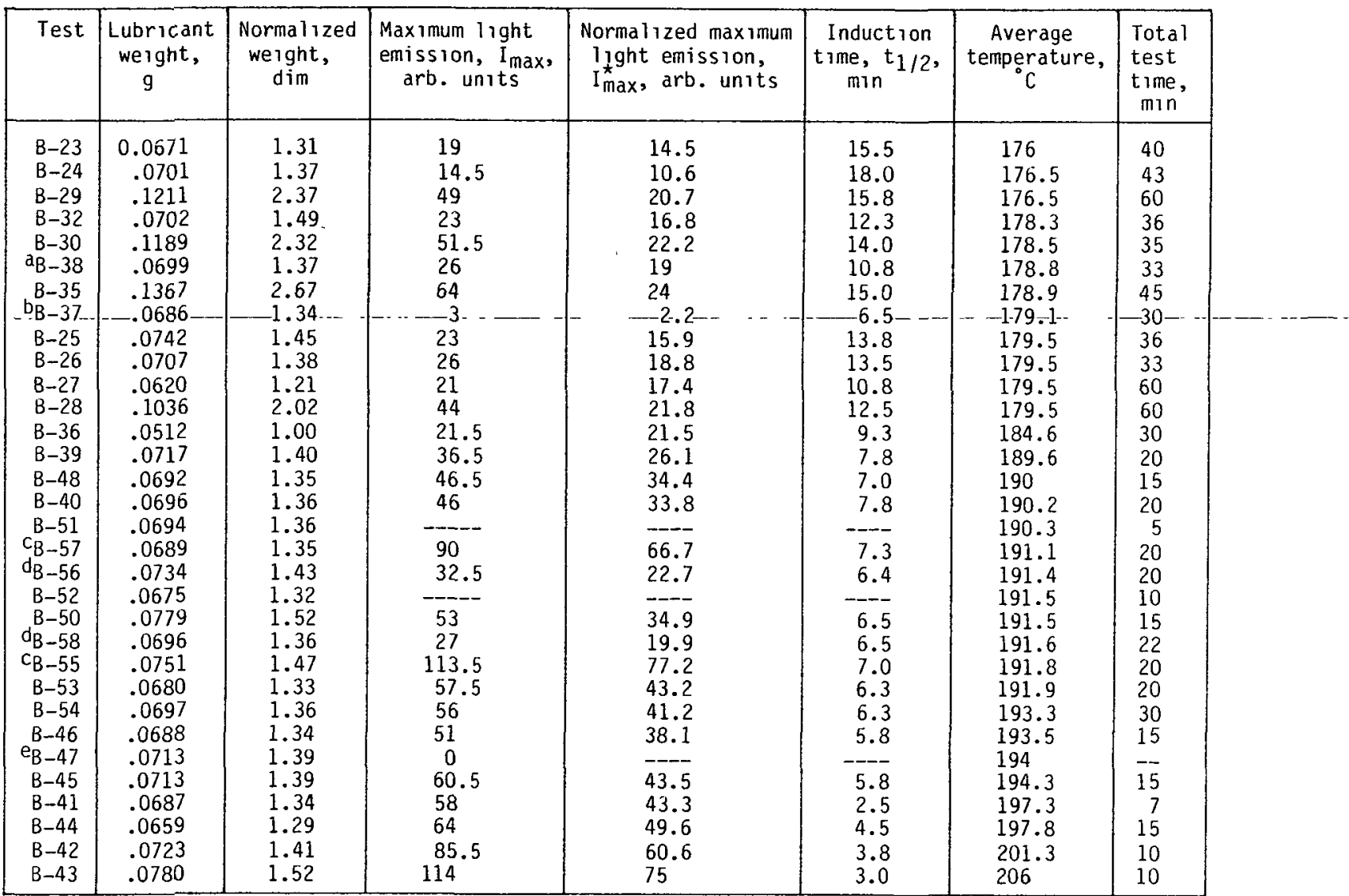

alnitrator added, azoisobutyronitrile $10^{-2} \mathrm{M}$ bNo intensifier

$c_{\text {Intens if ier concentration, } 2 \times 10^{-3} \mathrm{M}}$

Intensifier concentration, $0.5 \times 10^{-3} \mathrm{M}$

eNo oxygen (Argon atmosphere) 


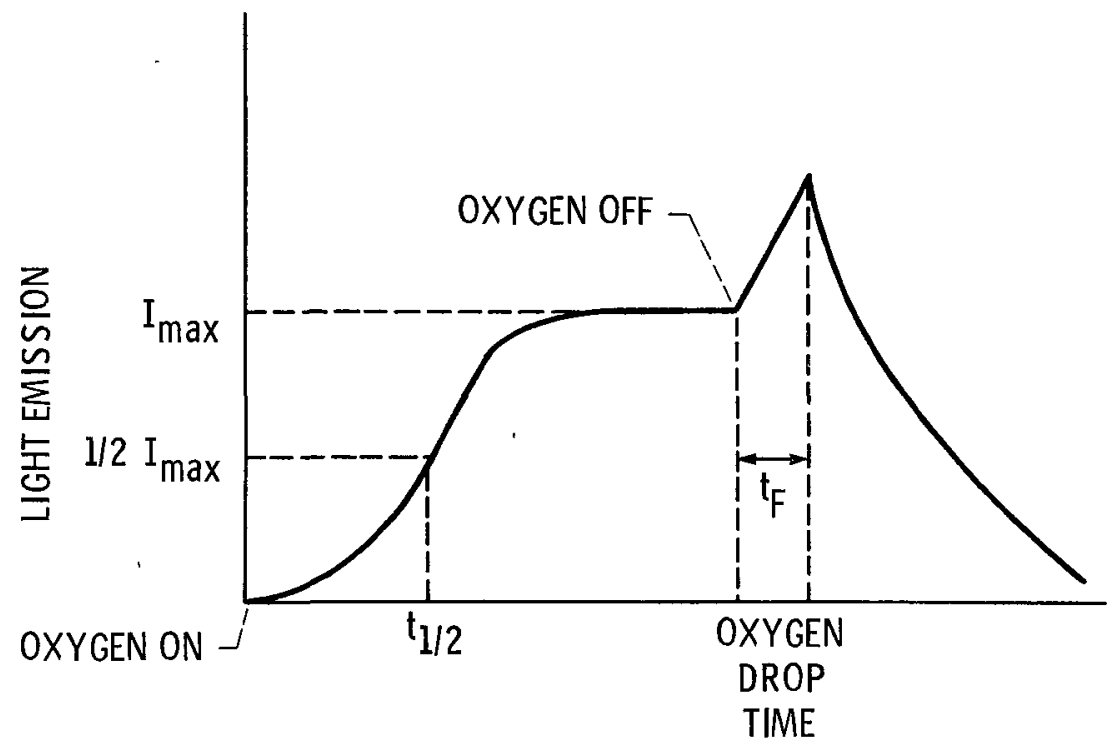

Figure 1. - Idealized curve of light emission as a function of time for an oxidation reaction. 


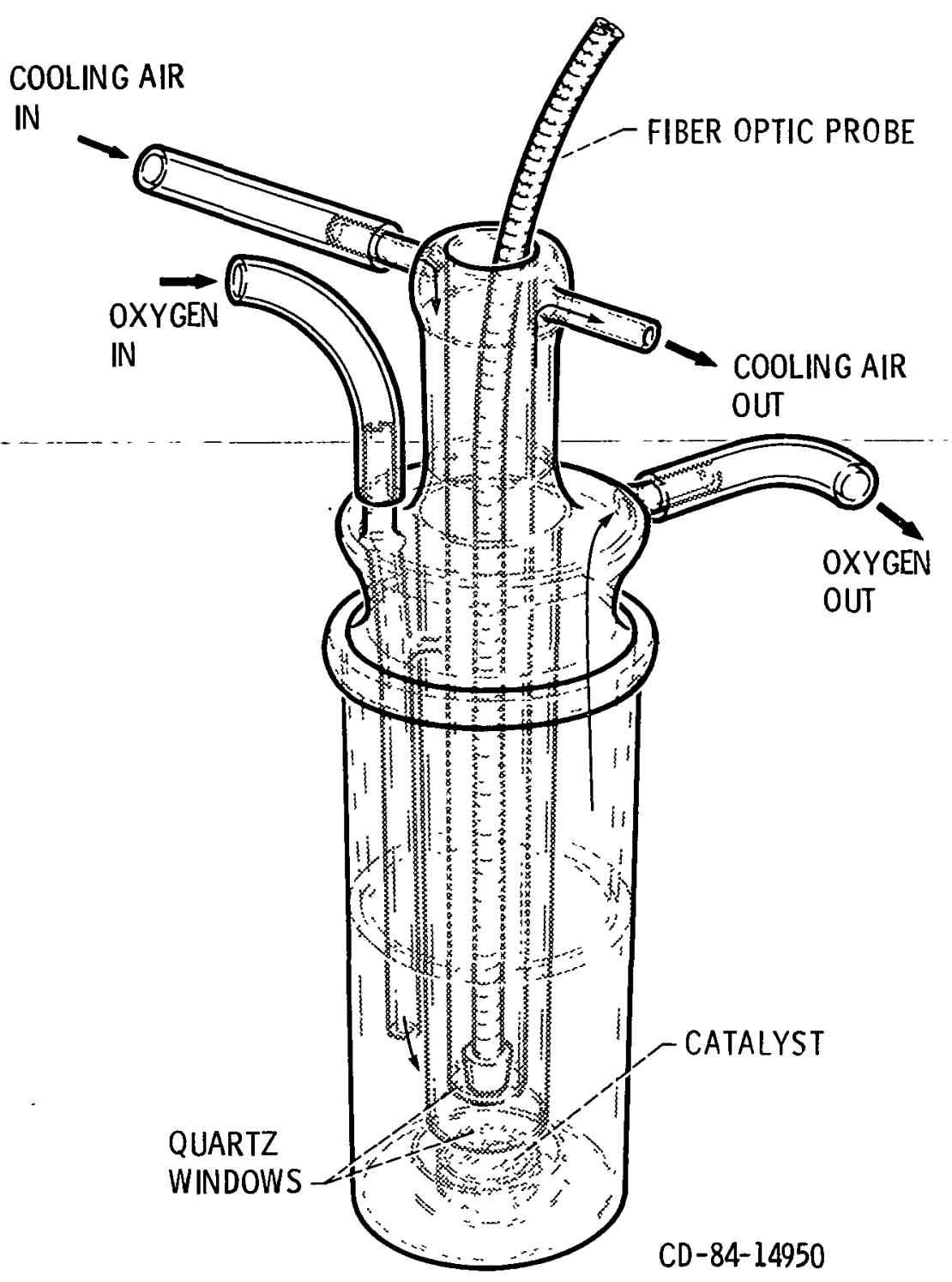

Figure 2. - Chemiluminescence micro-oxidation apparatus. 


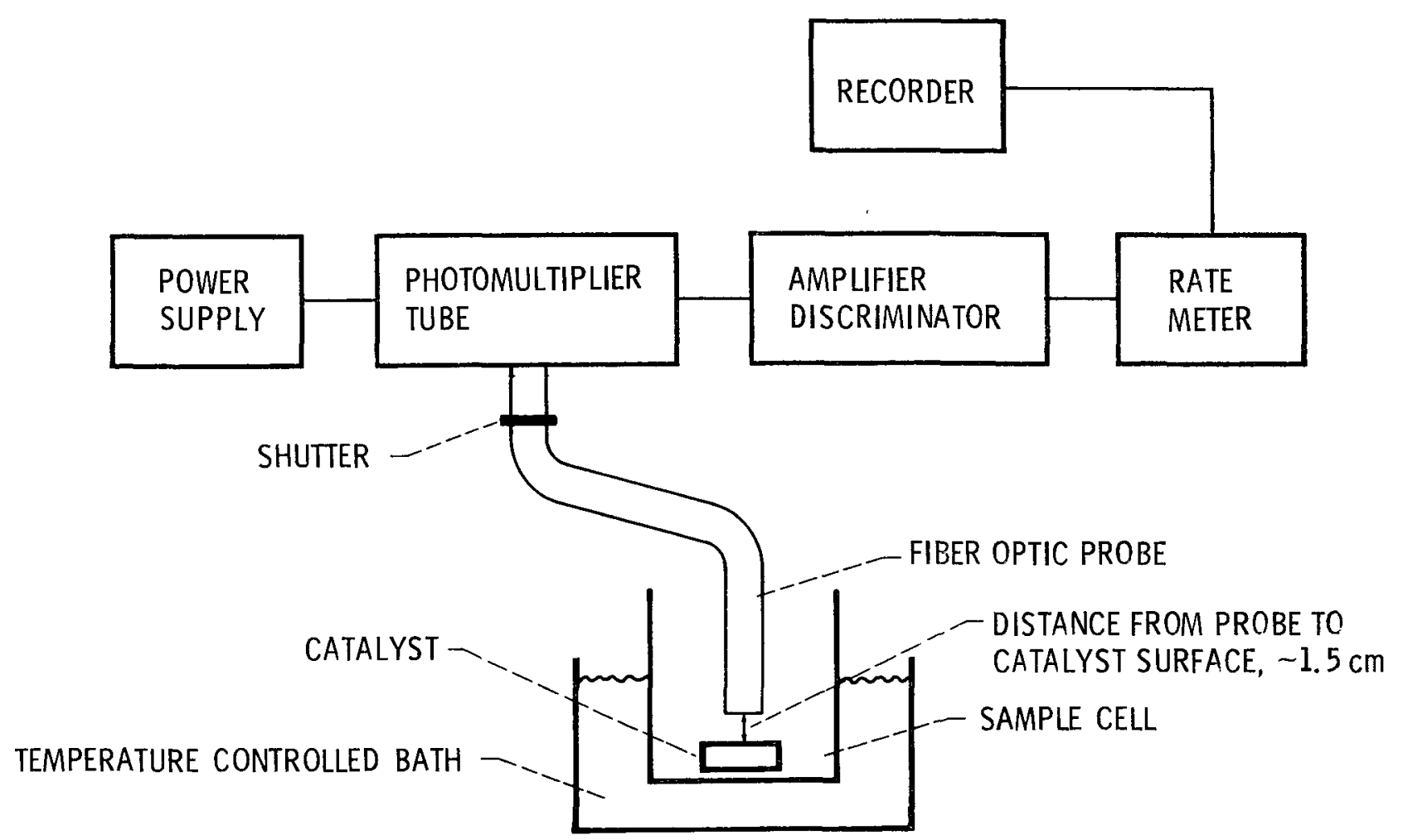

Figure 3. - Schematic of chemiluminescence apparatus. 


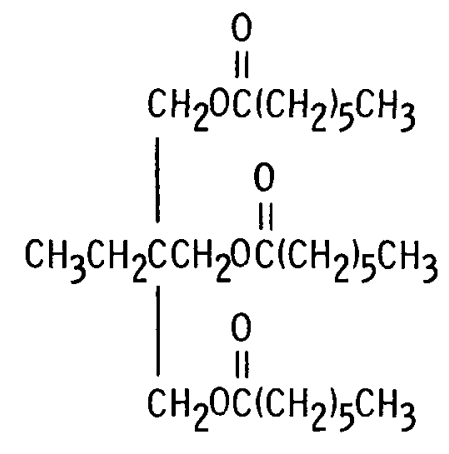

(a) Trimethyolpropane triheptanoate.

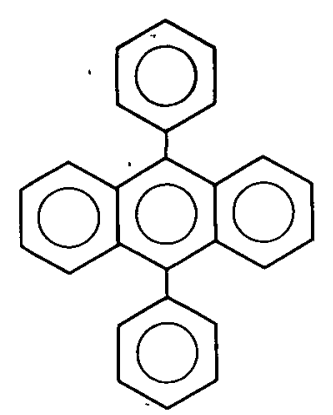

(b) 9, 10-Diphenylanthracene.

Figure 4. - Chemical structures. 

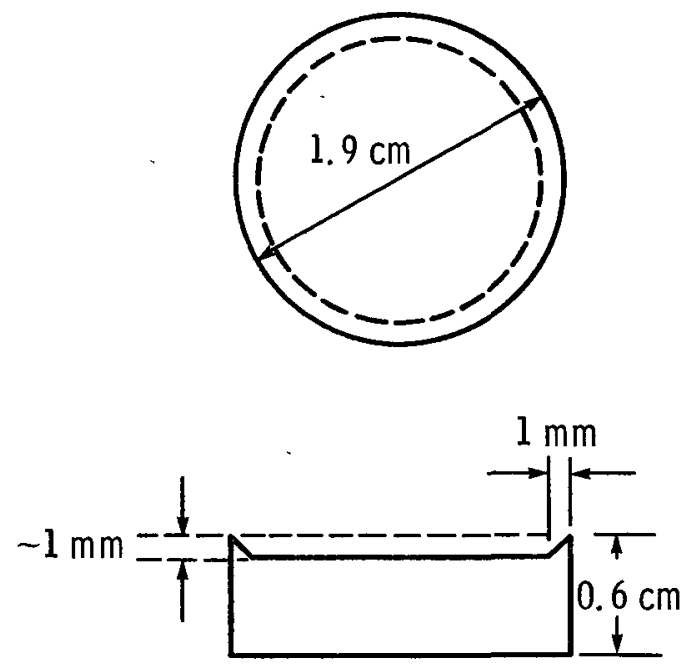

Figure 5. - Catalyst dimensions.

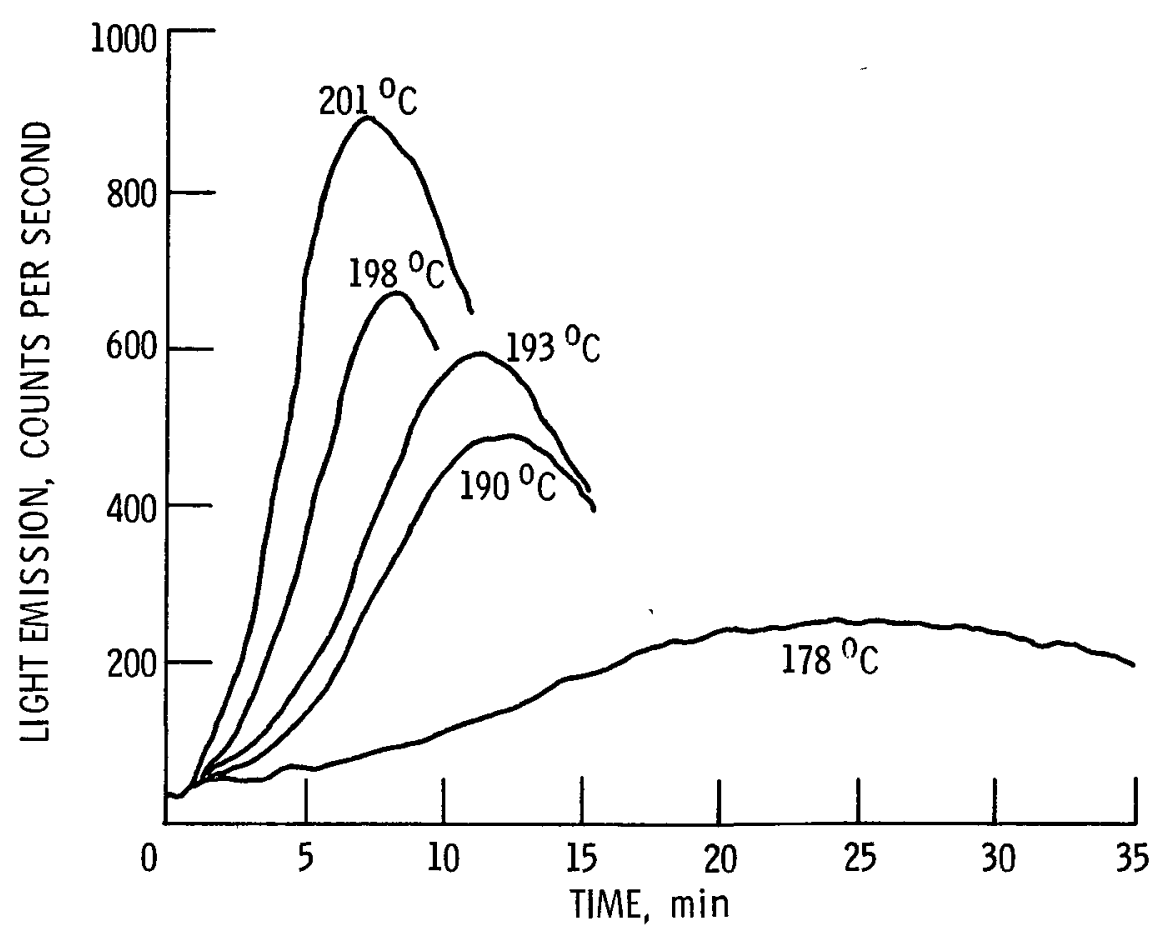

Figure 6. - Chemiluminescence as a function of time for trimethyolpropane triheptonate $+10^{-3} \mathrm{M}$ diphenylanthracene at various temperatures (aluminum 2024 catalyst, oxygen atmosphere). 


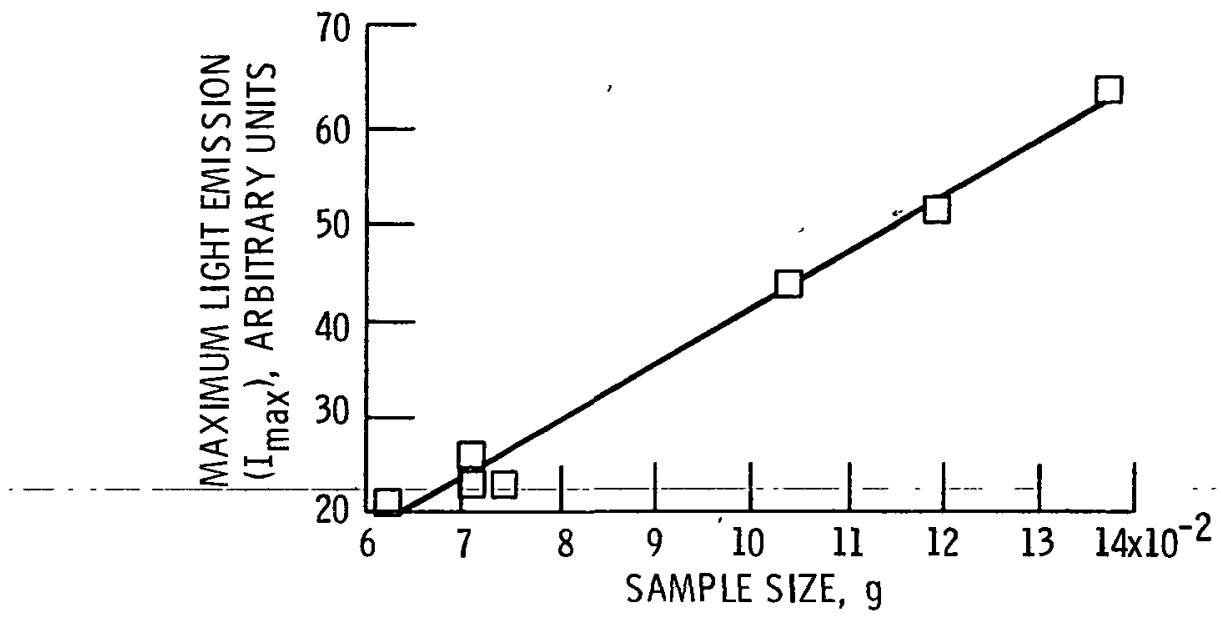

Figure 7. - Maximum light emission $\left(\mathrm{I}_{\max }\right.$ ) as a function of sample size, 178.3 to $179.5^{\circ} \mathrm{C}$, DPA $\left(10^{-3} \mathrm{M}\right)$ in TMPTH, aluminum 2024 catalyst, oxygen atmosphere.

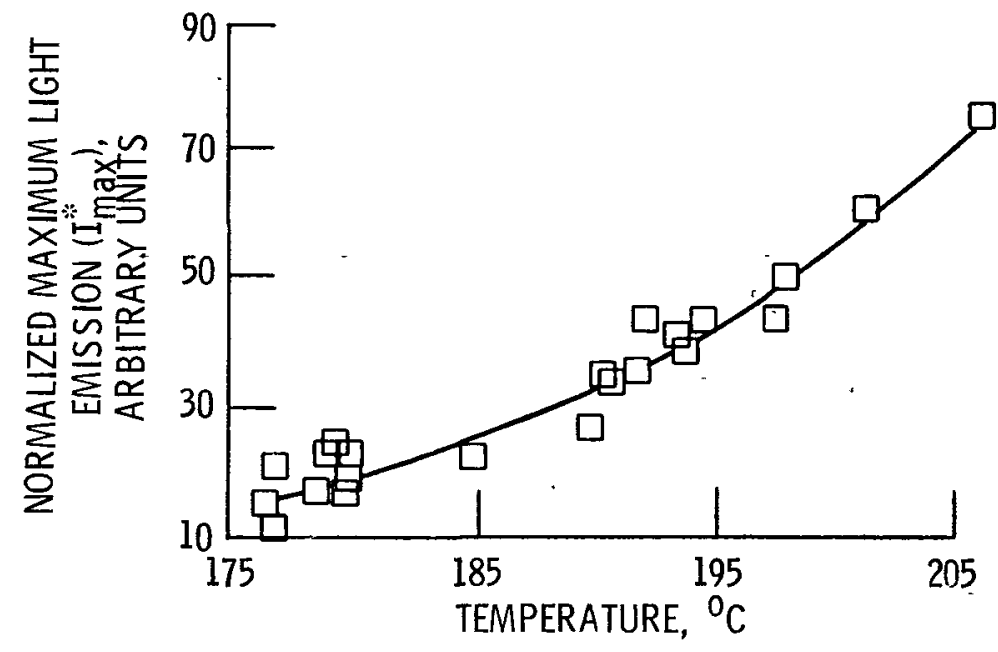

Figure 8. - Normalized maximum light emission $\left(\mathrm{I}_{\text {mą }}^{*}\right)$ as a function of temperature, DPA $\left(10^{-3} \mathrm{M}\right)$ in TMPTH, aluminum 2024 catalyst, oxygen atmosphere. 

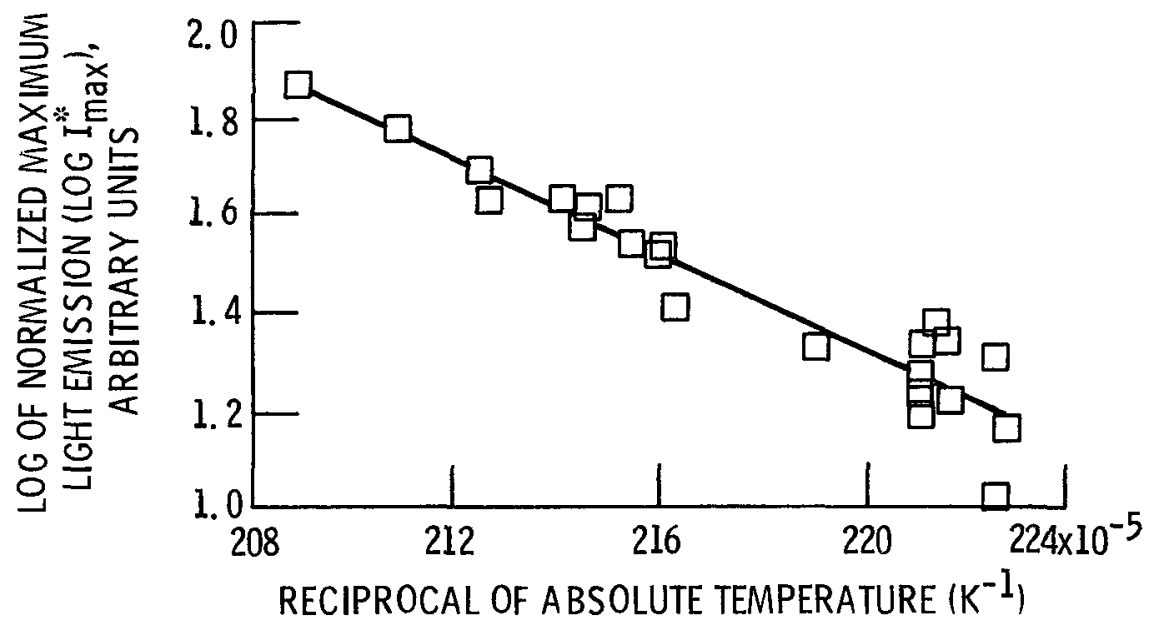

Figure 9. - Log of normalized maximum light emission ( $\log I_{\max }$ ) as a function of the reciprocal of the absolute temperature, DPA $\left(10^{-3} \mathrm{M}\right)$ in TMPTH, aluminum 2024 catalyst, oxygen atmosphere.

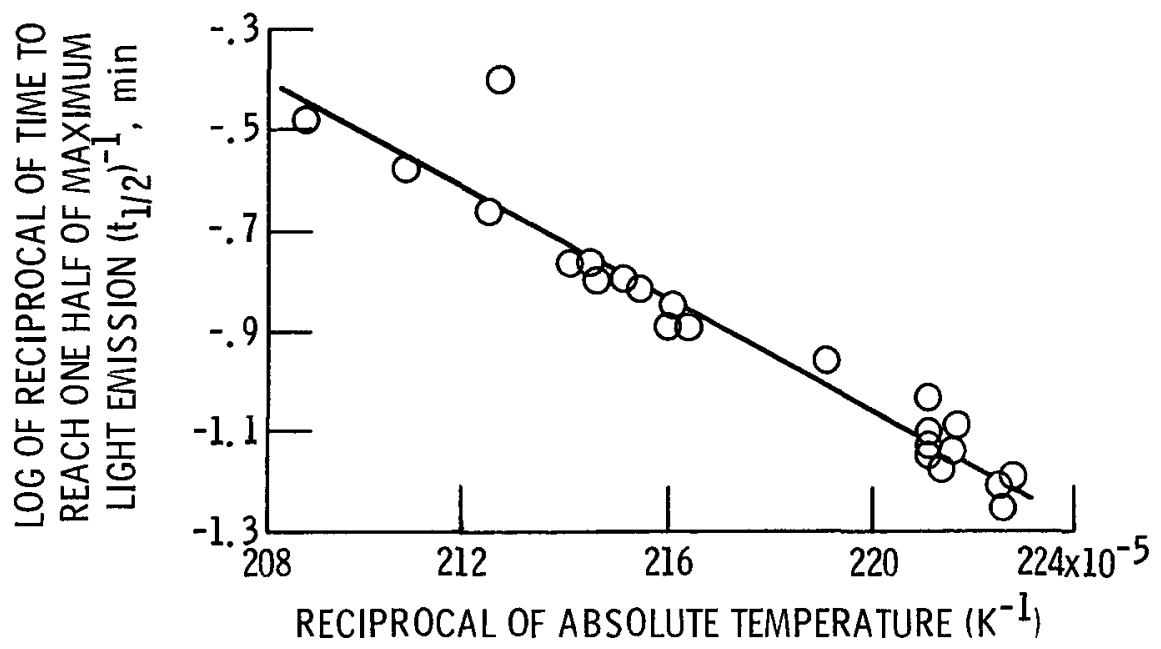

Figure 10. - Log of reciprocal of time to reach one half of maximum light emission $\left(\mathrm{t}_{1 / 2}\right)^{-1}$ as a function of the reciprocal of absolute temperature $\left(\mathrm{K}^{-1}\right)$, DPA $\left(10^{-3} \mathrm{M}\right)$ in TMPTH, aluminum 2024 catalyst, oxygen atmosphere. 


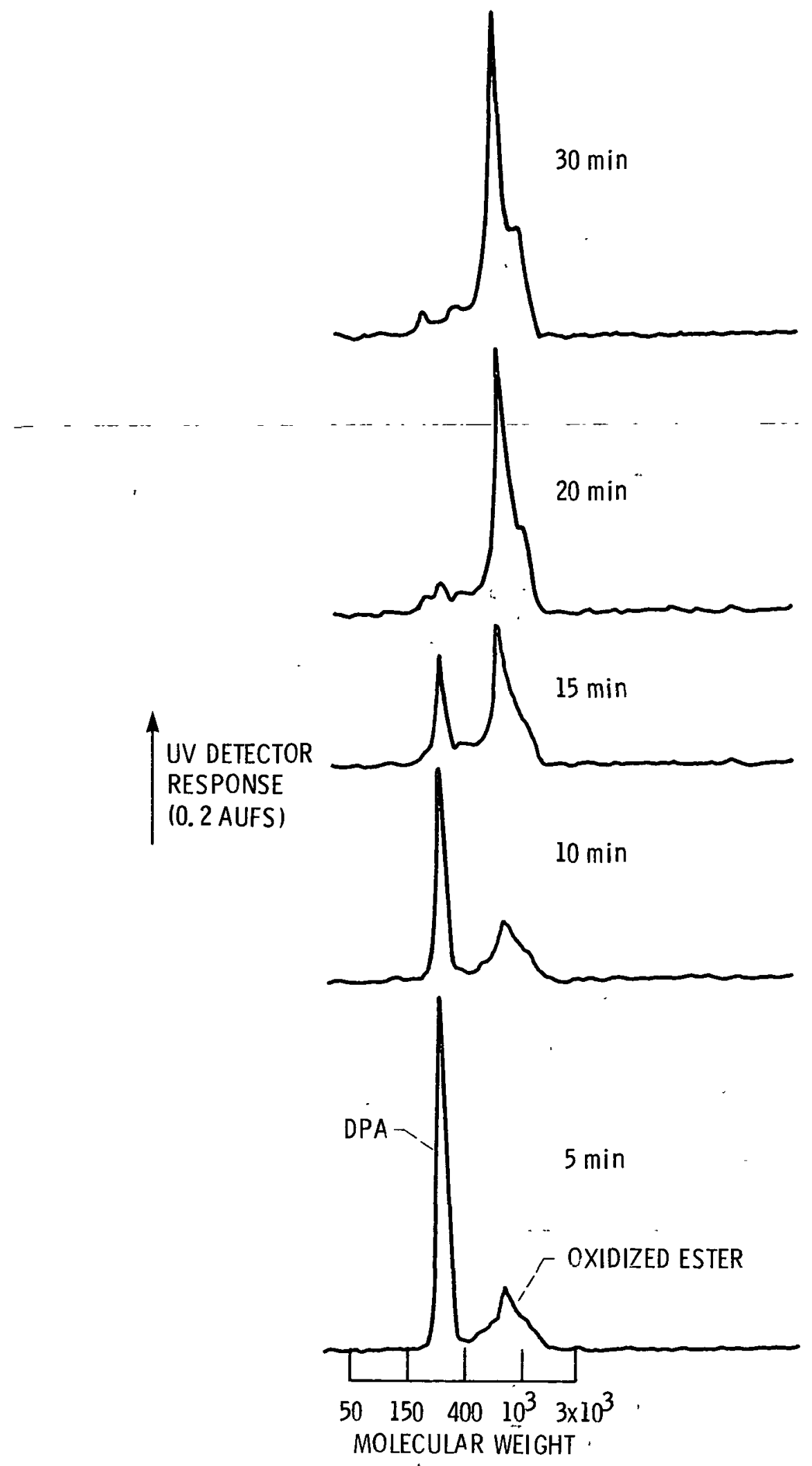

Figure 11. - Size exclusion chromatograms of oxidized TMPTH $+10^{-3}$ M DPA at various test times (temperature 190 to $193^{\circ} \mathrm{C}$. aluminum 2024 catalyst, oxygen atmosphere). 


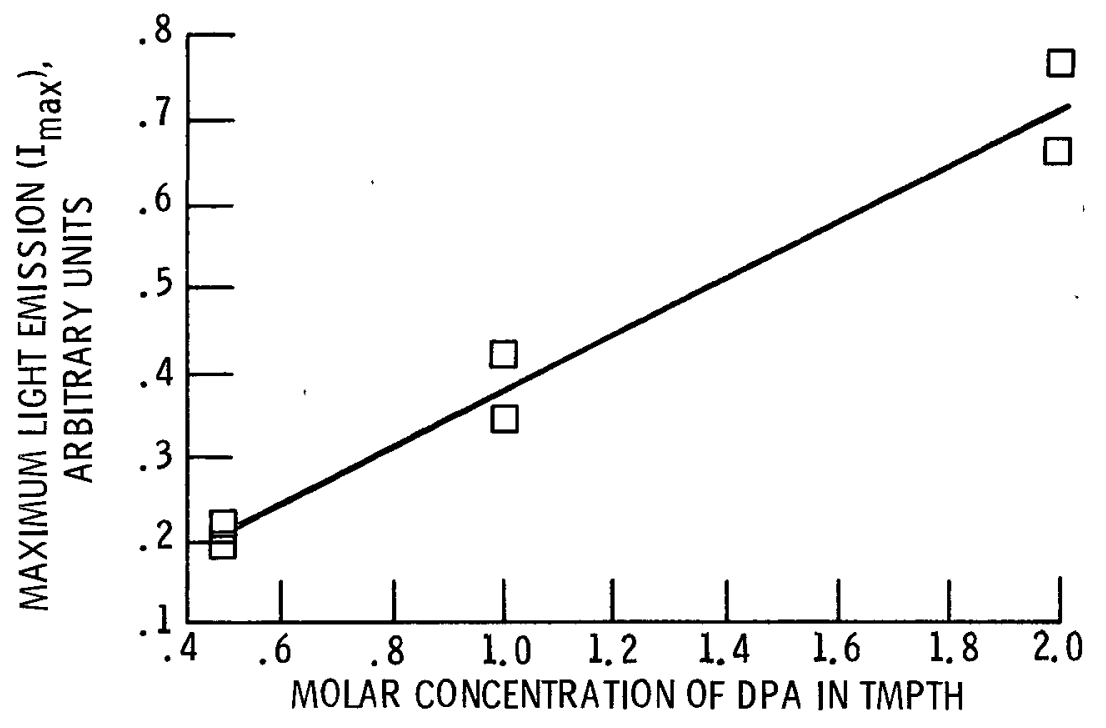

Figure 12. - Maximum light emission ( $I_{\max }$ ) as a function of molar concentration of diphenylanthracene (DPA) TMPTH, aluminum 2024 catalyst, 191 to $192{ }^{\circ} \mathrm{C}$, oxygen atmosphere.

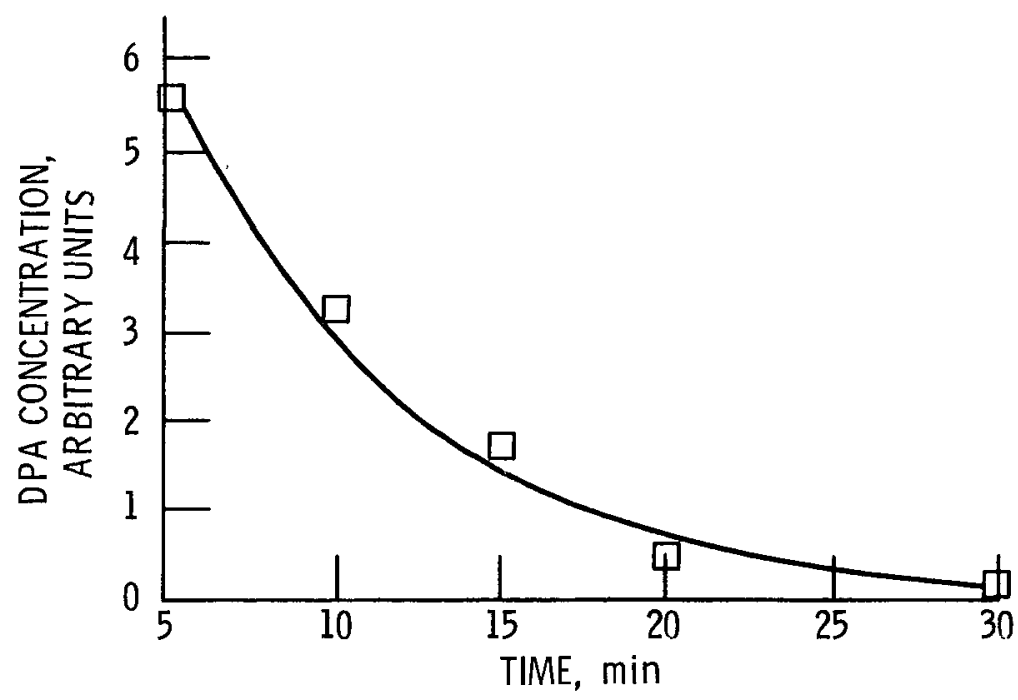

Figure 13. - Concentration of diphenylanthracene as a function of test time $\left(190\right.$ to $193^{\circ} \mathrm{C}$, aluminum 2024 catalyst, oxygen atmosphere). 


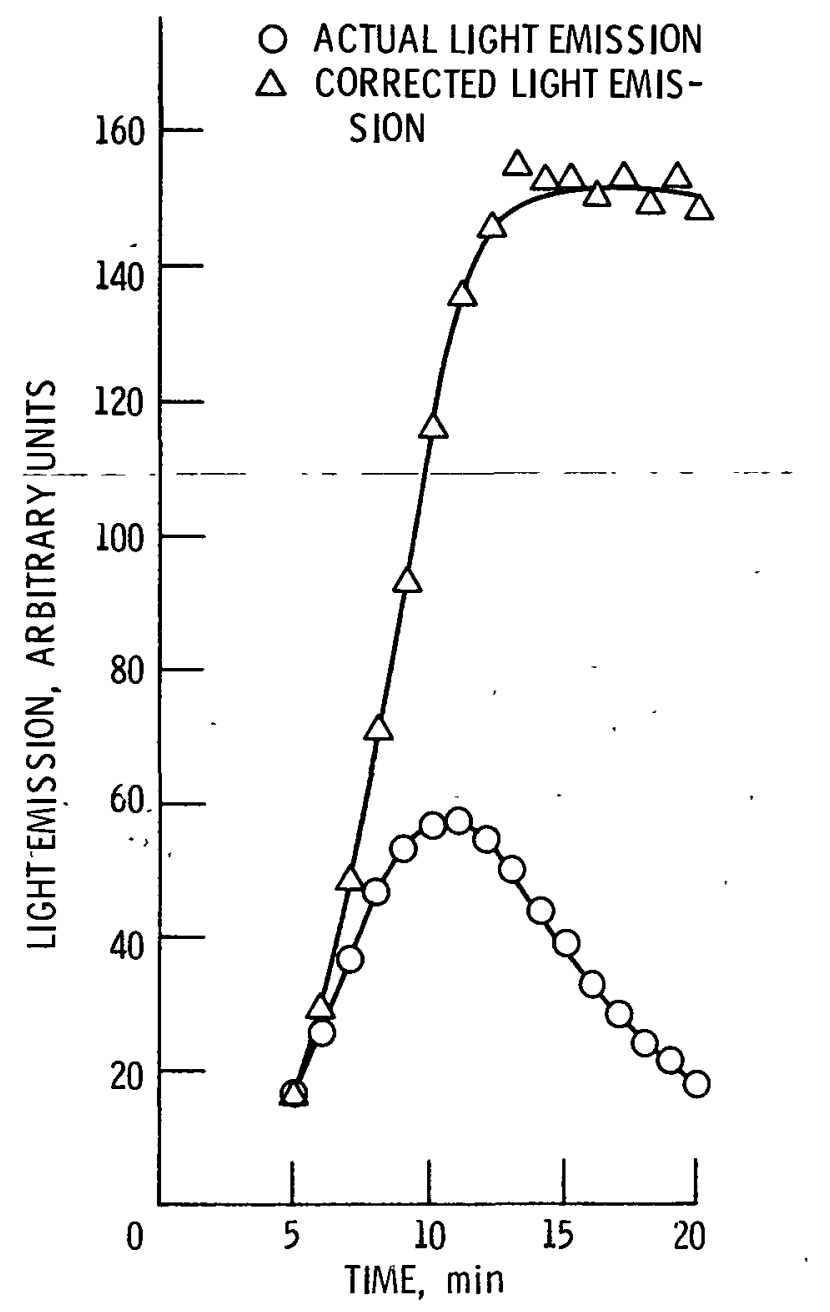

Figure 14. - Actual light emission as a function of time for test B-53 and emission corrected for DPA depletion $\left(191.9^{\circ} \mathrm{C}\right.$, aluminum 2024 catalyst, oxygen atmosphere). 


\begin{tabular}{|c|c|c|c|}
\hline $\begin{array}{l}\text { 1. Report No. } \\
\text { NASA TM-87242 }\end{array}$ & \multicolumn{2}{|c|}{2 Government Accession No. } & 3. Recipient's Catalog No. \\
\hline \multirow{3}{*}{\multicolumn{3}{|c|}{$\begin{array}{l}\text { 4. Title and Subtitle } \\
\text { A Preliminary Study of Ester Oxidation on an } \\
\text { Aluminum Surface Using Chemiluminescence }\end{array}$}} & 5. Report Date \\
\hline & & & \\
\hline & & & $\begin{array}{l}6 \text { Performing Organization Code } \\
505-63-01\end{array}$ \\
\hline \multirow{3}{*}{\multicolumn{3}{|c|}{$\begin{array}{l}\text { Willilam R. Jones, Jr., Michael A. Meador, and } \\
\text { Wilfredo Morales }\end{array}$}} & 8. Performing Organization Report No. \\
\hline & & & $E-2647$ \\
\hline & & & 10. Work Unit No \\
\hline \multirow{3}{*}{\multicolumn{3}{|c|}{$\begin{array}{l}\text { Performing Organization Name and Address } \\
\text { National Aeronautics and Space Administration } \\
\text { Lewis Research Center } \\
\text { Cleveland, Ohio } 44135\end{array}$}} & \\
\hline & & & 11. Contract or Grant No. \\
\hline & & & 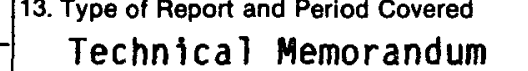 \\
\hline \multicolumn{3}{|c|}{12 Sponsoring Agency Name and Address } & \\
\hline \multicolumn{3}{|c|}{$\begin{array}{l}\text { National Aeronautics and Space Administration } \\
\text { Washington, } 0 . C . \quad 20546\end{array}$} & 14. Sponsoring Agency Code \\
\hline \multicolumn{4}{|c|}{$\begin{array}{l}\text { 15. Supplementary Notes } \\
\text { Prepared for the } 1986 \text { Annual Meeting of the American Society of Lubrication } \\
\text { Engineers, Toronto, Canada, May } 12-15,1986 \text {. }\end{array}$} \\
\hline \multicolumn{4}{|c|}{$\begin{array}{l}\text { The oxidation characteristics of a pure ester (trimethyolpropane trineptanoate) } \\
\text { were studied by using a chemiluminescence technique. Tests were run in a thin- } \\
\text { film micro-oxidation apparatus with an aluminum alloy catalyst. Conditions } \\
\text { included a pure oxygen atmosphere and a temperature range of } 176 \text { to } 206{ }^{\circ} \mathrm{C} \text {. } \\
\text { Results indicated that oxidation of the ester (containing } 10^{-3} \mathrm{M} \text { diphenylan- } \\
\text { thracene as an intensifier) was accompanied by emission of } 11 \text { ight. The maximum } \\
\text { intensity of light emission ( } I_{\text {max }} \text { ) was a function of the amount of ester, the } \\
\text { concentration of intensifier, and the test temperature. The induction period or } \\
\text { the time to reach one-half of maximum intensity (t } 1 / 2 \text { ) was an inverse function } \\
\text { of test temperature. Decreases in light emission at the later stages of a test } \\
\text { were caused by depletion of the intensifier. }\end{array}$} \\
\hline \multicolumn{2}{|c|}{17 Key Words (Suggested by Author(s)) } & \multirow{2}{*}{\multicolumn{2}{|c|}{$\begin{array}{l}\text { 18. Distribution Statement } \\
\text { Unclassified - unlimited } \\
\text { STAR Category } 27\end{array}$}} \\
\hline \multicolumn{2}{|c|}{ Chemiluminescence; Lubricants; Oxidation } & & \\
\hline $\begin{array}{l}\text { 19. Security Classif. (of this report) } \\
\text { Unc las s if ied }\end{array}$ & $\begin{array}{l}\text { 20. Security Classif (of th } \\
\text { Uncla }\end{array}$ & page) & 21. No. of pages \\
\hline
\end{tabular}

*For sale by the National Technical Information Service, Sprıngfield, Virgınıa 22161 
- Vatıonal Aeronautıcs and

Space Admınıstratıon

Lewis Research Center

Cleveland Ohı 44135

Otficial Business

Penalty for Private Use $\mathbf{5 0 0}$
SECOND CLASS MAIL

ADDRESS CORRECTION REQUESTED

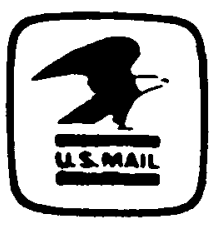

Postage and Fees Paid National Aeronautics and Space Administration NASA-451 